\title{
Cyrillic Transliteration and Its Users
}

\section{Alena L. Aissing}

A wide diversity exists in the current practice of transliterating Cyrillic scripts for use in bibliographic records in online catalogs. Without knowing which transliteration table was used, it is difficult to retrieve the desired record successfully or efficiently. Retrieving an item (e.g., titles or an author's name) from a library's online catalog (OPAC) where it is given only in transliterated form can be a confusing task, even for users who know the Russian language or at least the Cyrillic alphabet. This study explores the problems besetting three groups of Russian-language students faced with romanized Cyrillic bibliographic records. It also tries to investigate students' ability in searching the Russian records romanized according to the Library of Congress (LC) transliteration table. Analysis of the test results show the students' success-and-error rate before and after instruction. The findings of this study establish that transliteration is one of the factors limiting access by Russian language students to the Slavic collections.

tudents in foreign language classes usually experience various difficulties in finding library materials in the languages they study. ${ }^{1}$ One of the most intractable problems confronts readers of Russian, since records they want to access have been modified (i.e, romanized) by transliteration or transcription into the Roman (English) alphabet. Transliteration is a process in which each character of the source language is converted into a character of the target language; for example, Russian спутник (companion, satellite) becomes sputnik. Translit- eration needs to be distinguished from transcription, in which the sounds of the source words are conveyed by letters in the target language. For example, an English transcription of former President Mikhail Gorbachev's name would have to be Gorbachoff, to reflect the way it is pronounced in Russian. ${ }^{2}$

There are several different transliteration systems for Cyrillic script used throughout the world. Most of the currently used systems are based on graphical and/or phonologic similarities between Cyrillic and the target language. However, not all transliteration

Alena Aissing is German and Slavic Studies Selector and Slavic Studies Cataloger at the University of Florida George A. Smathers Libraries, Gainesville, Florida 32611.

The author wishes to express her appreciation to the Department of Germanic and Slavic Languages and Literatures at the University of Florida, the Department of Modern Languages at Florida State University, the Department of Slavic Languages and Literatures at the University of Illinois at Urbana-Champaign for their cooperation; Olga Campora and Graig N. Packard from the Center of Applied Linguistics in Washington, D.C., for valuable information in the field of Slavic linguistics; Joan Aliprand from the Research Libraries Group for inspiration, editing and updates on computer software developments; Frank DiTrolio, Dolores Jenkins, and John Van Hook from the Collection Management Department at University of Florida Libraries for editing this manuscript; Bill Covey from the Systems Department at the University of Florida Libraries for editing the statistical analysis and my husband, Gerrard Aissing, for encouragement and input on this research design. This research was funded in part by a grant, from the University of Florida, Division of Sponsored Research. 
or transcription is systematic. Both transliteration and transcription depend on the source and target language, and differ from case to case (see table 1). A searcher has to be aware of the array of variations in transliteration schemes, particularly if the search is being done in more than one database. ${ }^{3} \mathrm{~A}$ transliteration scheme that is systematic does not necessarily have a broad application. For example, the transliteration scheme used by Physical Review is intended for scholarly application. The Library of Congress transliteration is intended for the general user and is standard for most academic libraries in the United States. Recently, the LC transliteration system in its simplified form (without the diacritics) has been appropriated by various scholarly publishing organizations. ${ }^{4}$

Since these problem areas could affect the student's academic performance, it is important to question the effectiveness of transliteration as a method for bibliographic control and its usefulness for the user. This phenomenon has been analyzed during the past years by several authors, although no research has been done involving actual users. ${ }^{5-9}$ This study tries to fill this gap by investigating whether bibliographic searches for transliterated Russian titles or names are difficult for someone who knows the Russian language or at least the Cyrillic alphabet. The data for this research were gathered using three-part tests. These tests were distributed among Russianlanguage students at the University of Florida, Florida State University, and the University of Illinois at Urbana-Champaign during the period 1990-1993.

\section{BACKGROUND AND LITERATURE REVIEW}

Several Cyrillic transliteration schemes have been proposed on the local, national, and international levels at various times. Some were attempts at correcting and improving existing schemes. Others came up with new proposals, such as Dekleva's Uniform Slavic Transliteration Alphabet (USTA) that consisted of ninety-seven graphemes combining Roman letters and diacritical marks. ${ }^{10,11}$ It was never adopted, however, probably because its features were unfamiliar to both English- and Slavicspeaking readers.

Because the number of Roman letters in the English alphabet is less than the number of Cyrillic letters in the Russian alphabet, most of the transliteration systems have to resort to the use of diacritics or letter combinations to achieve a com-

TABLE 1

EXAMPLE OFTRANSLITERATION OFTHE WORDS पHTA, XIEБHभШA AND FШKEBHY IN VARIOUS TRANSLITERATION SYSTEMS

\begin{tabular}{llllll}
\hline \hline System & читальня & System & хлебница & System & Юшкевич \\
\hline LC & chital'nia & LC & khlebnitsa & BM & Yushkevich \\
ISO & cital'nja & ISO & hlebnica & NUC (LC) & IUshkevich \\
BSI & chital'nya & NYPL & khlebnitza & GNC & Juskevic \\
MR & cital'nya & SR & khlebnica & OFC & Iouskevich \\
\hline
\end{tabular}

Abbreviations used in this table

\begin{tabular}{|c|c|c|c|}
\hline LC & Library of Congress & SR & Slavic Review \\
\hline ISO & $\begin{array}{l}\text { International Organization for } \\
\text { Standardization }\end{array}$ & BM & British Museum \\
\hline BSI & British Standards Institution & NUC & National Union Catalog \\
\hline JYPL & New York Public Library & GNC & German National Catalog \\
\hline MR & Mathematical Review & OFC & Old French Catalog \\
\hline
\end{tabular}


plete transliteration. ${ }^{12}$ This can present several problems for the users of the catalog who have to deduce how these diacritics or letter combinations translate back to the original Cyrillic characters. ${ }^{13}$ The differences among the various schemes are considerable, especially for those Cyrillic letters for which no Roman equivalent exists: ë, $ж, x, ц, ч, ш, щ$, ю, and $я .{ }^{14}$ In addition, Russian has no $h$ and represents this sound mostly as $r$, therefore, transliterating Hamlet from Cyrillic back to Roman script results in Gamlet. ${ }^{15}$ A Russian name beginning with я might be transliterated into $i a, j a$, or ya with major retrieval problems unless the conversion system is known. A further problem is that certain phonemes characteristic of Slavic languages cannot be written unambiguously as a single Roman letter (assuming English pronunciation). ${ }^{16}$

The Library of Congress offers a separate transliteration table for every Slavic language written in Cyrillic scripts. ${ }^{17}$ This can lead to more inconsistencies. For example, $\mathrm{e}$ is used when transcribing Ukrainian $\epsilon$ and old Russian $\mathbf{t}$. That is, the same combination of Roman letters is used for two completely different Cyrillic letters! The user has to know or recognize the original language in order to find the corresponding transliteration when searching the library's online catalog.

Readers of non-Roman documents usually want to see the original script, because it is more familiar to them than the romanized version. ${ }^{18}$ Cyrillic script has been implemented on a number of systems. The first American library to automate Cyrillic script was the New York Public Library, where Cyrillic script records were included in its book-form "Dictionary Catalog," phototypeset from machine-readable copy. ${ }^{19}$ Cyrillic script capability was added to the Research Libraries Information Network (RLIN) in $1986 .{ }^{20}$ Cyrillic is one of the scripts implemented on ALEPH, the Israeli library system. ${ }^{21,22}$ The British Library's online catalog includes not only the characters of modern Cyrillic script but also Old Church Slavonic. ${ }^{23}$ VTLS, Geac, and
$\mathrm{IME}^{24}$ have contracts to develop systems for Russian libraries; Cyrillic script capability is a fundamental requirement.

Few American libraries have taken advantage of these developments because of the pervasive belief that romanization is adequate for those languages written in Cyrillic script. (The results of this study undermine this belief.) Because of this conviction, most libraries do not own systems that can utilize other scripts, nor do they have enough funding and concern for the multilingual needs of their community. ${ }^{25}$ Users cannot search and display a bibliographic record in the script of the original document. ${ }^{26}$ Most local OPACs are limited to Roman character sets and do not provide the proper typographical facilities necessary for the display of non-Roman languages. Therefore, romanization of non-Roman scripts is necessary if the automated catalog is to be a comprehensive representation of the library's holdings. ${ }^{27}$

\section{Most local OPACs are limited to Roman character sets and do not provide the proper typographical facilities necessary for the display of non-Roman languages.}

Yet there are some hopeful signs that this situation is changing. Several authors have discussed the problems for users caused by romanization, and the attitude of librarians toward minority users is changing. ${ }^{28}$ Allen and Plumer cite many examples of practices and methods that tend to alienate a library's international clientele: awareness is the first step toward correction. ${ }^{29}, 30$

Recent developments in computer software and standards will eventually do away with this limitation. ${ }^{31-34}$ In the past, research and formulation of standards for the automation of non-Roman scripts was slow and fragmentary. In addition, the library community developed its own standards in isolation from the standards-making of the computer industry. ${ }^{35}$ These standards were incorporated into USMARC and UNIMARC. ${ }^{36,37}$ 
Today, there is a new universal multiscript character set, International Standard ISO/IEC $10646 .^{38}$ The Unicode ${ }^{\mathrm{TM}}$ character set, which is code-for-code identical with ISO/IEC 10646, is being implemented in products from leading computer companies. ${ }^{39}$ The advent of this new standard facilitates the development of global software capable of processing any script. No longer will libraries have to develop systems on their own; many of the features needed for multiscript processing will be included in the standard package or can be added easily. This will be a boom to the users of various non-Roman scripts. Service to the user and provision for the most direct access to dissimilar documents (i.e., documents not in the predominant script used by the library) need to be seen as the prime responsibilities of libraries.

\section{RESEARCH DESIGN AND METHODOLOGY}

\section{Pretest}

A sample of 50 Russian language students was randomly chosen from the Department of Germanic and Slavic Languages and Literatures at the University of Florida during the spring semester of 1991. None of the students was familiar with the LC transliteration table. The data were collected using three tests consisting of a list of titles and proper names in Russian. The students were then asked to transliterate the Russian items on the list. The objective of these tests was to determine: Test AHow correct are the students' searches without the knowledge of the transliteration table and what are the problems involved? Test B-How correct are the students' searches after receiving instruction and practicing the transliteration in the library? Another test (C) consisted of retrieving and locating at least three items-one title search, one author search, and one journal search. Most of the students visited the library, located the items, and brought back the call numbers and the location codes of the materials requested. Test B was then given to the students after they practiced what they learned from my instruction.
I tried to ascertain whether they still had problems and how much they had improved. After the data were statistically analyzed, the findings showed that without the knowledge of the LC transliteration practice of Russian letter я by $\mathrm{A}$, for example, 80 percent of the students chose ya, whereas only 7 percent were correct. When students had to deal with Russian w (phonetically very similar to English sh), 91 percent were successful even without knowing how to transliterate. It is likely that any grapheme transliterated by a letter combination for which the English pronunciation does not resemble the Russian sound becomes a barrier to access. This pretest concentrated on transliteration of only 7 letters - those for which transliteration could be problematic: я,ю, ц, щ, й, х, and ж. None of the students was able to transliterate all 7 tested letters correctly (the average correct score of the tested individuals was only 1.1 correct out of 7). The instruction and approximately one week practice resulted in an overall improvement in the scores for the individual letters (the average score increased to 4.3 out of 7). Results of a paired $t$-test indicated that the improvement of the test scores is highly significant $(t=0.001)$. Finally, only 14.6 percent of the students were able to transliterate all 7 letters. ${ }^{40}$

\section{Actual Research}

Because the sample size was rather small and the Department of Germanic and Slavic Languages and Literatures at the University of Florida offers only undergraduate classes in Russian, inferences from the data analyses were limited and showed a high degree of uncertainty. To get a more reliable picture of the problem, the study was extended to include more students from Florida State University and the University of Illinois, including graduate students. One hundred forty-five undergraduate and graduate Russian language students from these three universities were the sample size for the actual research. The randomly selected students were tested by the use of three 
specifically designed tests and a questionnaire. Tests A and B were similar to those used in the pretest, consisting of a list of Russian proper names and titles in an (ideally) isomorphic representation of the title pages of several actual documents in the Cyrillic alphabet. ${ }^{41}$ In both tests, special attention was given to those graphemes that cannot be rebuilt reversibly and to those that are difficult to transliterate: я,ю, ц, щ, й, х, and ж. Test $\mathrm{A}$ was intended to investigate how successful the students would be in searching and retrieving transliterated records without any instruction. This also showed how well the library had been preparing students in the past. Test $B$ was given to the students after they were instructed in the use of a transliteration table. This transliteration table was a simplified form of the LC transliteration table for the Russian language without the diacritical marks. (Diacritical marks are generally ignored in OPAC indexing.) The results would indicate whether there was significant improvement or whether there were still residual problems. Test $\mathrm{C}$ included both transliterated titles and proper names where no part of the original data remains unchanged, and the matching process can become cumbersome. This is exactly how the student would find the bibliographic data on an OPAC display screen in the library. The students had to show how they were able to decode, reverse, match, and identify the names of authors or titles of works back into the Cyrillic script. In other words, the users had to match each letter of the romanized script with the original alphabet equivalent. For a reader familiar with the language and the original script of the work, the transliteration could be a serious obstacle resulting in partial or even total loss of information. This test, therefore, tended to indicate the obstacles in the matching process.

At the end of the testing, each student was asked to fill out a questionnaire. This questionnaire was developed to assess not only transliteration use but also primary library use patterns and utilization of collections, services, and facilities by Russian-language students. Basic demographic data such as number of years in school were collected as well. Additional information about the users (education, library use, problems with online searching, their personal opinions, etc.) was used in interpreting the tests. For example, if the student did not use the library often, the probability in making errors in online searching might be relatively higher. The Russian-language students were asked:

- whether they use library services;

- whether they were familiar with the library's online catalog/OPAC;

- whether they had problems with retrieving English bibliographic records;

- whether they had problems with retrieving Russian bibliographic records;

- whether they were familiar with the LC transliteration table; and

- whether they would prefer using and displaying the Cyrillic alphabet, etc.

The data were compiled, tabulated, and analyzed using the statistical software JMP, version 2.0 for the Macintosh. ${ }^{42}$

\section{FINDINGS}

\section{Success-Failure Report}

Test A. Students transliterated a list of selected titles and names in the Russian language with no prior instruction and no transliteration table provided. Students had to create their own search structures depending on whatever knowledge of Russian phonology and orthography they had, making use of their own concept of transliteration. In some cases, the result was a combination of translation, transliteration, and transcription. Out of 145 students who took test A, 14 partially translated the Russian words into English instead of transliterating them. Table 2 shows the frequency distribution of number of mistakes by the number of students who made them. There were 93 letters (19 words) in test A. Commonly encountered titles, such as Александр Сергеевич Пушкин or России первая ^ юбовь, were used. The largest possible number of mistakes was 93 , since there were 93 letters. Test results showed that in any situation of not knowing the 
TABLE 2

NUMBERS OF ERRORS MADE IN TESTS A AND B

\begin{tabular}{ccccc}
\hline & \multicolumn{2}{c}{ Test A } & \multicolumn{2}{c}{ Test B } \\
\cline { 2 - 5 } Interval & Count & $\%$ & Count & $\%$ \\
\hline 0 & 0 & 0 & 20 & 15 \\
$1-5$ & 4 & 3 & 59 & 43 \\
$6-10$ & 19 & 13 & 20 & 15 \\
$11-15$ & 28 & 19 & 13 & 9 \\
$16-20$ & 25 & 17 & 7 & 5 \\
$21-25$ & 26 & 18 & 6 & 4 \\
$26-30$ & 12 & 8 & 5 & 4 \\
$31-35$ & 15 & 10 & 2 & 1 \\
$36-40$ & 6 & 4 & 2 & 1 \\
$>40$ & 10 & 7 & 3 & 2 \\
Total & 145 & & 137 & \\
\hline
\end{tabular}

"The difference in total counts was due to the fact that some students did not participate in the second test.

transliteration table, none of the students would be able to conduct a 100 percent successful search. The lowest number of mistakes made was one, and only one person achieved this rate. The average number of mistakes made was 21.6. The largest group of students, 28, made between 11 and 15 mistakes.

For a reader familiar with the language and the original script of the work, the transliteration could be a serious obstacle resulting in partial or even total loss of information.

Test B. Test B consisted of 82 letters (in 16 words) which included words similar to the ones used in the first test (for example, in examining the soft vowel $я$, test Aincluded the word первая and test B had the word современная). Table 2 showed the frequency distribution of mistakes by the number of students who made them. The table shows that the library instruction and practice resulted in a clear overall improvement. Twenty students transliterated all 82 characters without any mistakes, followed by 59 students who made fewer than 6 mistakes in their search structure. This con- stituted the largest student unit, forming 43 percent of the total sample. Only one person had all 82 letters wrong. The average number of mistakes made was 8.9 .

Special attention was given to the letters that either cannot be rebuilt reversibly and to those that must be transliterated by letter combinations. These letters were я,ю, й, ц, ш, х, ж, ч, and щ. The results for these letters are compiled in figure 1 . In the comparison of the two tests significant improvement is seen. It also becomes clear that the students are dealing with two groups of letters: those that represent sounds similar to the ones encountered in the English language and those that represent sounds that are alien to English speakers. The improvement in the second group is more impressive than that experienced in the first group. The first group consists of the letters ц, ч, and ш, whereas the second group is formed byю, я, й, x, ж, and щ. In the first group the average improvement after instruction is almost negligible; in the second group it is always more than 27 percent. It also seems that the vowels are more difficult to transliterate than the consonants. A good example of the problems in transliterating Cyrillic letters is given by the 


\section{Count}

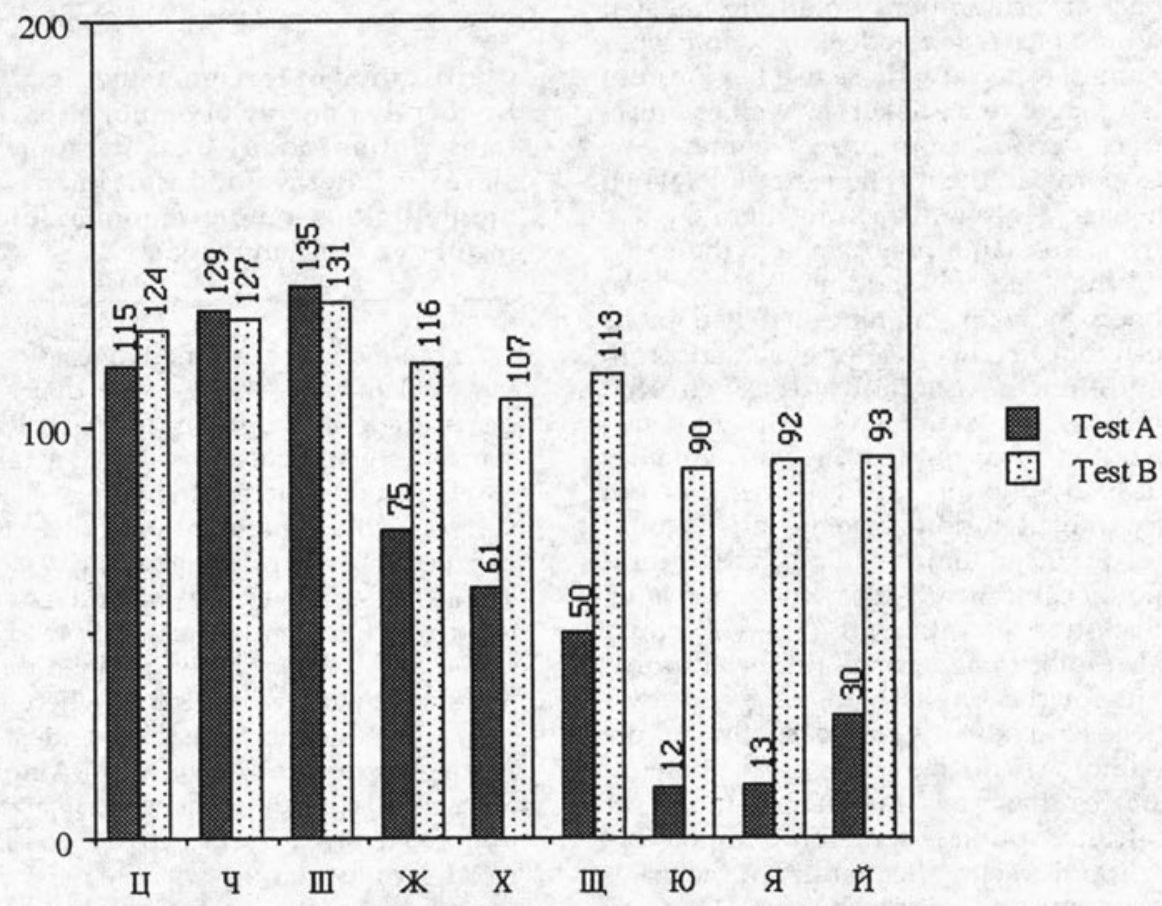

Letter

FIGURE 1

Comparison of Test A and Test B for the Letters Я, Ю, Ц, Ш, Х, Ж, Ч, Щ, and Й

letter ю. In modern American English there are several ways one could write this sound, including ewe, yu, you, or even $\mathrm{u}$. In fact, the version used by LC " $\mathrm{Q}$ " is counterintuitive, because there seems no relation between the transliteration and the everyday "sound" of the Cyrillic letter.

Test C. After instruction, test $C$ was given to the students as well. This test included a list of transliterated Russian titles and authors' names. If a student were to search a book written in a Cyrillic script in the online catalog, this would be the way in which it would display. The user then would have to match the transliterated information with its Cyril- lic version and reestablish the text in its original characters to determine if a given record matches the one sought for.

The reconstruction or back-transliteration can be performed only between two alphabetic scripts and depends on the rules governing the relationships between the letters of these two scripts. ${ }^{43}$ Applying the rules of transliteration in reverse can cause some difficulties since this process involves at least three different stages: (1) the user must know how the word appears in the original (i.e., Cyrillic) alphabet; (2) the user needs to know how to use the transliteration rules; (3) the user should be skilled in recognizing that this transliterated 
information does indeed match its original equivalent. Obviously, users will discover this only if they apply the back-transliteration. An additional step would be needed in dealing with proper names, especially those used in Western languages (e.g., Baker) as well as adjectives derived from proper names (e.g., Copernican theory). For example, when a user deals with a transliterated text from Russian alphabet where the name "Brown" is included, the user needs to know how this name is spelled in its original (in this case English script). In addition, the user needs to be aware that the Russian version will be Браун. Cyrillization of foreign names is frequently done by phonological transcription, not by transliteration since the latter would result in an unintelligible and unpronounceable result to a Russian reader. Back-transliteration of "Браун" could also refer to a German author "Braun," but for the English language, the user needs to know the correct spelling of the name. This example clearly demonstrates that back-transliteration and/or retranscription is sometimes impossible without tracing the identity of the original name and its spelling.

Figure 2 shows the frequency distribution of mistakes made by students. on test C. The data were collapsed into 16 groups showing that after instruction, 3 students did not make any mistake in reversing the transliteration process.
The largest group, consisting of 20 students, made 3 mistakes while only 5 students made as many as 16 to 17 mistakes.

\section{Cyrillization of foreign names is frequently done by phonological transcription, not by transliteration since the latter would result in an unintelligible and unpronounceable result to a Russian reader.}

Another factor examined in test $\mathrm{C}$ was the total number of mistakes that students made individually for each Russian letter. This analysis is shown in table 3 , where as predicted, the letters $ю$ and $я$, (represented combinations of two Roman letters when romanized) caused a lot of trouble. The most misunderstood letter was и (140 mistakes), followed by ы (94) and й (80). The underlined parts of the following words show where the students made most mistakes on test C: Андрей Яхонтов, София, ларец Мариц Медичи; сборник фантастических прикґючений, закон пруподы. The word "прилючений" was the most difficult for students to transliterate. The transliterated word "prikliuchenir"" is the genitive plural of "приключение" (in English adventure). Since the Russian language changes its noun endings in particular cases, the user needs to take this into consideration when transliter-

TABLE 3

ERROR COUNT FROM TEST C BY LETTER

\begin{tabular}{|c|c|c|c|c|c|}
\hline Letter & Count & Letter & Count & Letter & Count \\
\hline a & 5 & 6 & 0 & B & 2 \\
\hline $\mathbf{r}$ & 1 & A & 3 & e & 15 \\
\hline ) & 1 & ж & 4 & 3 & 10 \\
\hline и & 140 & й & 80 & $\mathbf{K}$ & 2 \\
\hline$\lambda$ & 3 & M & 1 & $\mathbf{H}$ & 5 \\
\hline o & 2 & п & 3 & $\mathrm{P}$ & 5 \\
\hline c & 1 & $\mathbf{T}$ & 10 & $y$ & 25 \\
\hline$\phi$ & 5 & $x$ & 35 & ц & 31 \\
\hline प & 11 & m & 11 & щ & 22 \\
\hline ЫI & 94 & ю & 90 & я & 96 \\
\hline
\end{tabular}




\section{Mistakes}

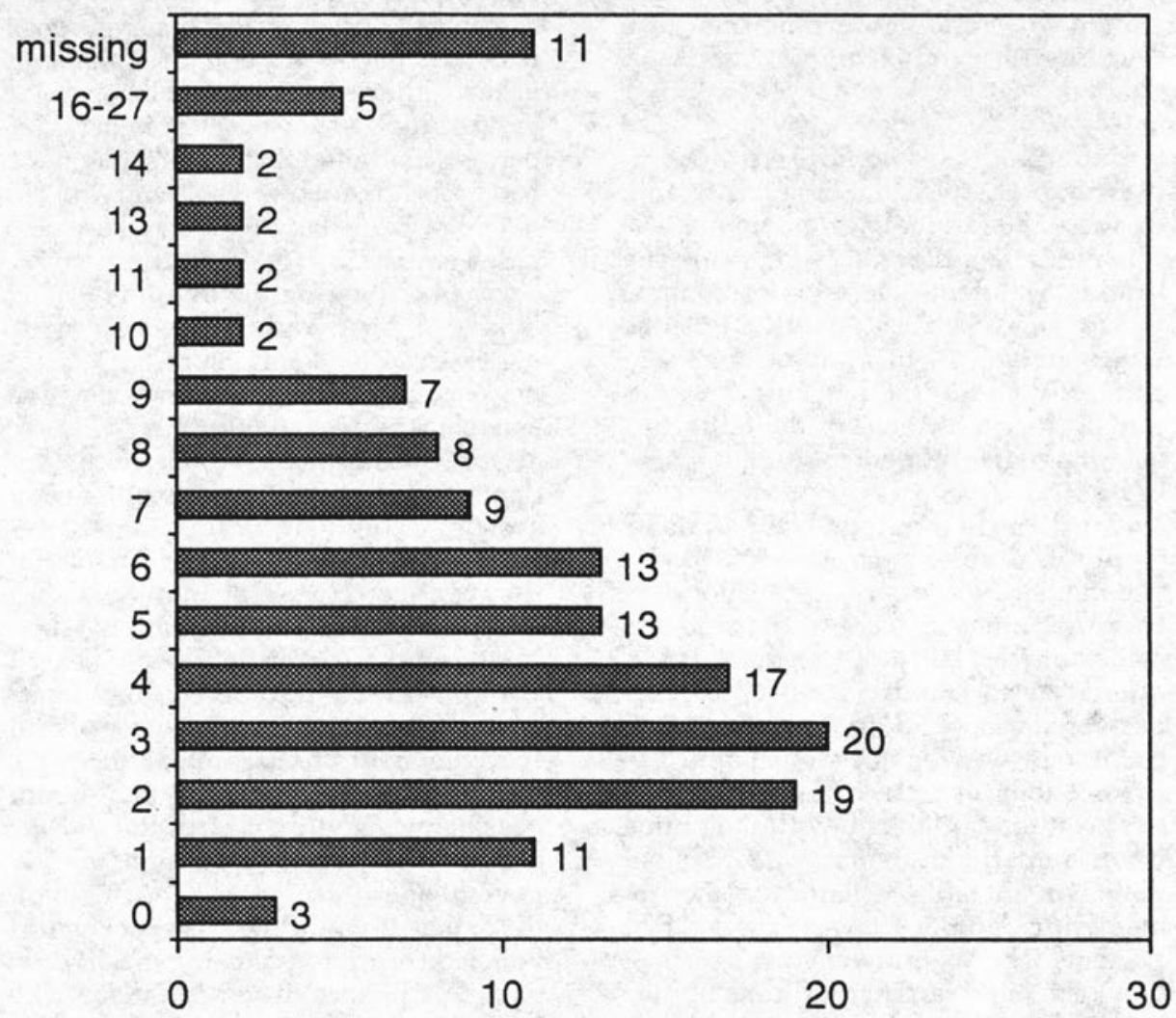

Number of Students

FIGURE 2

Frequency Distribution of Mistakes Made by Students on Test C

ating from Russian and/or back-transliterating into Russian. When students dealt with transliteration of the word "прикиючений," in most cases, they omitted one of the last letters or substituted the English letter y for them. (Phonetically Russian й is considered identical with the English y as in yes.) Even though transliteration assumes following the rule of "write what you see" (i.e., performing exclusively orthographic transliteration where the user should concentrate only on the letters not on their sounds), the example above demonstrates that the users attempted to base their transliteration on both orthographic and phonetic rules at the same time. In practice, it could mean that all bibliographical transliteration systems contain some elements of phonological transcription that are based on the historical habit of pronouncing certain letters in a certain way. These habits are probably acquired in childhood, and it is just as difficult to change them as any other phonetic attributes of articulation such as stress, pitch, and intonation. The study shows 
that the students tend to transliterate according to the spelling and pronunciation convention governing their own (i.e., English) language.

\section{Questionnaire}

Undergraduates comprised the largest group of students (79 percent), and, of these, 40 percent were seniors. The remaining 21 percent were primarily graduate students. Only 1 percent of the group were Ph.D. students. Thus the data gathered in this survey represent primarily undergraduate students' patterns rather that those of the total Russian-language student population (see table 4).

One of the first questions the students were asked in the survey was "Do you use the library services?" In response to this question, 9 percent of the students said that they did not use the services offered by the library while 85 percent answered yes. Nine students (6 percent) did not answer the question at all.

Additional analysis of the relationship between the familiarity with the online catalog and the students' years in school is shown in table 4. Based on the frequency distributions, it was expected that students who spent more years at school would be more familiar with the library online catalog and the concept of bibliographic access. Table 4 shows this to be primarily the case. Of those students who were freshmen, only 35 percent said that they were familiar with the online catalog, while 65 percent of graduate students and 100 percent of doctoral students re- ported that they were familiar with the online catalog in the library.

Another question of the survey dealt with the students' experience of problems in the retrieval of Russian bibliographic records. Table 5 shows that 37 students ( 26 percent) answered that they "sometimes" had problems, followed by those who did not know ( $28=19$ percent $)$ and those who answered no ( $27=19$ percent).

When answering the question "What kind of problems did you have in retrieving a Russian bibliographic record?" 48(33 percent) students indicated transliteration as a major problem (table 6).

One question also dealt with students' familiarity of the transliteration system. Table 7 indicates that 73 respondents (50 percent) indicated that they can search Russian materials with the help of the transliteration table. Those who felt that they could search without a table numbered 40 (28 percent) and 2 students ( 1 percent) said that they could not search at all.

To find out students' opinion about possible use and display of the Cyrillic alphabet in their online search, the following question was asked: "Do you think that it would be easier for you if you had the option of using the original Cyrillic alphabet in your search?" The majority of the Russian-language students (105 $=72$ percent) answered yes.

\section{IMPLICATIONS}

The intent of this study is to examine the public reaction to online retrieval of material involving Cyrillic script trans-

TABLE 4

FAMILIARITY WITH ONLINE CATALOG, BY YEARS IN SCHOOL

\begin{tabular}{|c|c|c|c|c|c|c|c|c|c|c|c|c|}
\hline \multirow[b]{3}{*}{ Familiarity with online catalog } & \multicolumn{12}{|c|}{ Years in School } \\
\hline & \multicolumn{2}{|c|}{ Freshman } & \multicolumn{2}{|c|}{ Sophomore } & \multicolumn{2}{|c|}{ Junior } & \multicolumn{2}{|c|}{ Senior } & \multicolumn{2}{|c|}{ Graduate } & \multicolumn{2}{|c|}{ Doctoral } \\
\hline & No. & $\%$ & No. & $\%$ & No. & $\%$ & No. & $\%$ & No. & $\%$ & No. & $\%$ \\
\hline Yes & 7 & 35 & 7 & 47 & 24 & 73 & 25 & 54 & 13 & 65 & 2 & 100 \\
\hline No & 5 & 25 & 3 & 20 & 4 & 12 & 9 & 19 & 3 & 15 & 0 & 0 \\
\hline Little & 8 & 40 & 5 & 33 & 5 & 15 & 12 & 26 & 4 & 20 & 0 & 0 \\
\hline Number of students & 20 & 14 & 15 & 10 & 33 & 23 & 46 & 32 & 20 & 14 & 2 & 1 \\
\hline
\end{tabular}

$X^{2}=11.12 ; d f=8 ;$ Cramer's $V=0.194$ 
TABLE 5

FREQUENCY DISTRIBUTION FOR PROBLEMS WITH ONLINE CATALOG IN GENERAL AND WITH RETRIEVAL OF RUSSIAN TITLES

\begin{tabular}{lcrcc}
\hline & \multicolumn{2}{c}{ Online Catalog } & \multicolumn{2}{c}{ Retrieval of Russian Titles } \\
\cline { 2 - 5 } Response & Frequency & $\%$ & Frequency & $\%$ \\
\hline Unknown & 28 & 19 & 14 & 10 \\
Always & 12 & 8 & 2 & 1 \\
Sometimes & 37 & 26 & 41 & 28 \\
Seldom & 10 & 7 & 28 & 19 \\
No & 27 & 19 & 41 & 28 \\
Never tried & 31 & 21 & 19 & 13 \\
\hline
\end{tabular}

TABLE 6

FREQUENCY DISTRIBUTION FOR KIND OF PROBLEMS WITH RETRIEVAL OF RUSSIAN TITLES

\begin{tabular}{lcr}
\hline $\begin{array}{l}\text { Kind of Problems } \\
\text { with Retrieval }\end{array}$ & Frequency & $\%$ \\
\hline Unknown & 76 & 52 \\
Transliteration & 48 & 33 \\
Diacritical marks & 3 & 2 \\
$\begin{array}{l}\text { Not familiar with } \\
\text { online catalog }\end{array}$ & 7 & 5 \\
Other & 11 & 8 \\
\hline
\end{tabular}

TABLE 7

FREQUENCY DISTRIBUTION FOR FAMILIARITY WITH TRANSLITERATION

\begin{tabular}{lcc}
\hline $\begin{array}{l}\text { Familiarity with } \\
\text { Transliteration }\end{array}$ & Frequency & $\%$ \\
\hline $\begin{array}{l}\text { Unknown } \\
\begin{array}{l}\text { Can search with } \\
\text { transliteration table }\end{array}\end{array}$ & 26 & 18 \\
$\begin{array}{l}\text { Can search without } \\
\text { transliteration table }\end{array}$ & 40 & 50 \\
$\begin{array}{l}\text { Cannot search at all } \\
\text { Needs help }\end{array}$ & 2 & 1 \\
\hline
\end{tabular}

literated into Roman letters in a primarily English-language environment. The difficulty of searching for transliterated Russian records for someone who is familiar with the Russian alphabet was tested, involving students at three universities. The analysis of the findings provides insight into the problems of Russian-language students when they try to access transliterated Cyrillic bibliographic records. These data enable the author to determine any statistical significance of particular variables on students' success-failure rate. As expected, the measurements strongly suggest that the use of transliteration in bibliographic records forms a barrier to access even for those skilled in the original script. Anumber of other factors, such as unfamiliarity with online searching and with library resources, exacerbates this problem, but such factors are, of course, not peculiar to language students. The important point is that, even after hours of instruction in the LC tables, most students still felt that searching in the original alphabet would be more efficient and easier. It seems likely that such feelings are not limited to the Cyrillic alphabet, but would apply to records in other nonRoman scripts as well.

Any academic library needs to examine its user population in order to develop and implement appropriate services. Assessing the needs of foreign-language students in American colleges or universities ought to be an integral part of library instruction programs. Because of the scale of the problem, library instruction for Russian-language students should not only be the responsibility of reference librarians but also of the Slavic studies faculty, too. Both groups must, on the strength of this study's findings, include a session on transliteration that will help students acquaint 
themselves with the system and teach them how to interpret particular characters in the Cyrillic script that could be troublesome.

Transitions in computer standards that support multiple-character sets in the libraries are predictably slow. Nevertheless, multiscript-character set, the Unicode standard/ISO 10646, that supersedes the traditional ASCII (American Standard Code Information Interchange) character set has been developed. Perhaps academic libraries will eventually acquire systems based on this new standard. Implementation of this sixteen-bit character encoding that can represent the principal written languages collected by American academic libraries, would mean a revolutionary change in serving foreign language students. It is up to the librarians, developers, and programmers to make the change.

\section{REFERENCES AND NOTES}

1. Virginia P. Sorensen, "Searching for Materials in a Foreign Language," Research Strategies 9 (Summer 1991): 152-55.

2. David Crystal, The Cambridge Encyclopedia of Language (Cambridge: Cambridge Univ. Pr., 1987), 346.

3. Catherine E. Pasterczyk, "Russian Transliteration Variations for Searchers," Database 8 (Feb. 1985): 68-75.

4. William Edgerton, "One More Look at the Problems of Transliteration," Slavic Review 48 (Winter 1989): 97-99.

5. International Federation of Library Associations and Institutions, "Transliteration Systems for the Russian Cyrillic Alphabet: Report on a Survey," International Cataloguing: Quarterly of the IFLA Committee on Cataloguing 5 (Apr./June 1976): 8.

6. Hans H. Wellisch, "Bibliographic Access to Multilingual Collections," Library Trends 29 (Fall 1980): 223-44.

7. George C. Steyskal, "A Plain-Letter Romanization for Russian," Library Resources and Technical Services (Spring 1980): 170-72.

8. K. Ahmad and G. G. Corbett, "Bilingual Terminals: Input and Output in Cyrillic and Roman Scripts," in FEOLL Workshop: Computer Simulation in University Teaching (Amsterdam: North Holland, 1981), 237-52.

9. Sylva Simsova, "Multilingual Information and the Computer," Information Development 1 (Apr. 1985): 103-108.

10. B. Dekleva, Uniform Slavic Transliteration Alphabet (USTA) (Berkeley, Calif.: Univ. of California Pr., 1973).

11. Graphemes are the smallest units in a writing system capable of causing a contrast in meaning. In the English alphabet, the switch from cat to bat introduces a meaning change; therefore, $\mathrm{c}$ and b represent different graphemes. For more information, see David Crystal, The Cambridge Encyclopedia of Language (Cambridge: Cambridge Univ. Pr., 1987), 194.

12. B. Weinberg, "Transliteration in Documentation," Journal of Documentation 30 (Mar. 1974): 18-31.

13. Hans H. Wellisch, "Script Conversion Practices in the World's Libraries," International Library Review 8 (Jan. 1976): 55-84.

14. - The Conversion of Scripts - Its Nature, History, and Utilization (New York: Wiley, 1978).

15. Susan MacDougal, The State of the Art in the Handling of Vernacular Scripts in Library Systems (Canberra: The Author, 1991).

16. Phonemes are the minimal units in the sound system of a language. For more information, see David Crystal, A Dictionary of Linguistics and Phonetics (Cambridge : Basil Blackwell, 1991): 258.

17. Library of Congress; Processing Services, LC Romanization Tables and Cataloging Policies (Metuchen, N.J.; Scarecrow, 1990).

18. Alena L. Aissing, "Computer Oriented Bibliographic Control for Cyrillic Documents with or without Script Conversion," Information Technology and Libraries 11 (Dec. 1992): 340-44. 
19. S. Michael Malinconico, Walter R. Grutchfield, and Erik J. Steiner, "Vernacular Scripts in the NYPL Automated Bibliographic Control System," Journal of Library Automation 10 (Sept. 1977): 205-25.

20. The Research Libraries Group News 10 (May 1986): 3-4.

21. "Panel on Cyrillic Systems: ALEPH, RLIN VTLS," International Federation of the International Library Associations and Institutions Satellite Meeting on Automated Systems for Access to Multilingual and Multiscript Library Materials (presented at second meeting held in Madrid: 1993) Proceedings (Munich: Saur, 1994).

22. Susan S. Lazinger, "ALEPH: Israel's Research Library Network: Background, Evolution, and Implications for Networking in a Small Country," Information Technology and Libraries 10 (Dec. 1991): 275-91.

23. Roger Butcher, "Multi-lingual OPAC Developments in the British Library," Program 27 (Apr. 1993): 165-71.

24. Information from respective vendors. The features of the VTLS system are described in "Panel on Cyrillic Systems" (see note 21 above).

25. Sylva Simsova, "Coping with Foreign and Nonstandard Character in Libraries," in John Eyre, ed., Small Computers in Libraries (London: Meckler, 1988), 13-15.

26. James Edward Agenbroad, Nonromanization: Prospects for Improving Automated Cataloging of Items in Other Writings (Washington D.C.: Library of Congress, 1992).

27. C. Summer Spalding, "Romanization Reexamined," Library Resources and Technical Services 21 (Jan. 1977): 3-21.

28. Joan M. Aliprand, "Nonroman Scripts in the Bibliographic Environment," Information Technology and Libraries 11 (June 1992): 105-19.

29. Mary Beth Allen, "International Students in Academic Libraries: A User Survey," College $\mathcal{E}$ Research Libraries 54 (July 1993): 323-33.

30. Plummer Alston Jones, Jr., "Cultural Oasis or Ethnic Ghetto," North Carolina Libraries 50 (Summer 1992): 100-105.

31. Mark Leggott, "Unique, Universal \& Uniform Character Encoding," Canadian Library Journal 48 (Oct. 1991): 345-46.

32. Charles Petzold, "Move Over, ASCII! Unicode Is Here," PC Magazine 12 (Oct. 1993): 374.

33. Charles Petzold, "Viewing a Unicode TrueType Font under Windows NT," PC Magazine 12 (Nov. 1993): 375.

34. Charles Petzold, "Typing Unicode Characters from the Keyboard," PC Magazine 12 (Dec. 1993): 426.

35. John Clews, Language Automation Worldwide (Harrogate: United Kingdom SESAME Computer Projects, 1988).

36. USMARC Specifications for Record Structure, Character Sets, Tapes, prepared by Network Development and MARC Standards Office (Washington, D.C.: Cataloging Distribution Service, Library of Congress, 1990).

37. Brian P. Holt, Sally H. McCallum and A.B. Long, UNIMARC Manual (London: International Federation of Library Associations and Institutions Universal Bibliographic Control and International MARC Programme, British Library Bibliographic Services, 1987).

38. Joint Technical Committee ISO/IEC JTC1, Information Technology-Universal Multiple-Octet Coded Character Set, Part 1: "Architecture and Basic Multilingual Plane, ISO/IEC 10646: 1993" (Geneva: International Organization for Standardization, 1993).

39. The Unicode Consortium, The Unicode Standard: Worldwide Character Encoding, Version 1.0 (Reading, Mass.: Addison-Wesley, 1991-92); supplemented by The Unicode Standard, Version 1.1 (prepublication ed.) (Mountain View, Calif.: Unicode Consortium, 1993). (Unicode is a trademark of Unicode, Inc.)

40. Alena L. Aissing, The Effectiveness of Cyrillic Transliteration (poster session given at the American Library Association Annual Conference, Atlanta, July 1991).

41. Isomorphic representation - data are expressed exactly as found in the original documents, in this case, in the Russian characters.

42. SAS Institute JMP User's Guide, Version 2.0 (Cary, N.C.: September 1989).

43. Alena L. Aissing, "Computer Oriented Bibliographic Control for Cyrillic Documents with or without Script Conversion," Information Technology and Libraries 11 (Dec. 1992): 340-44. 


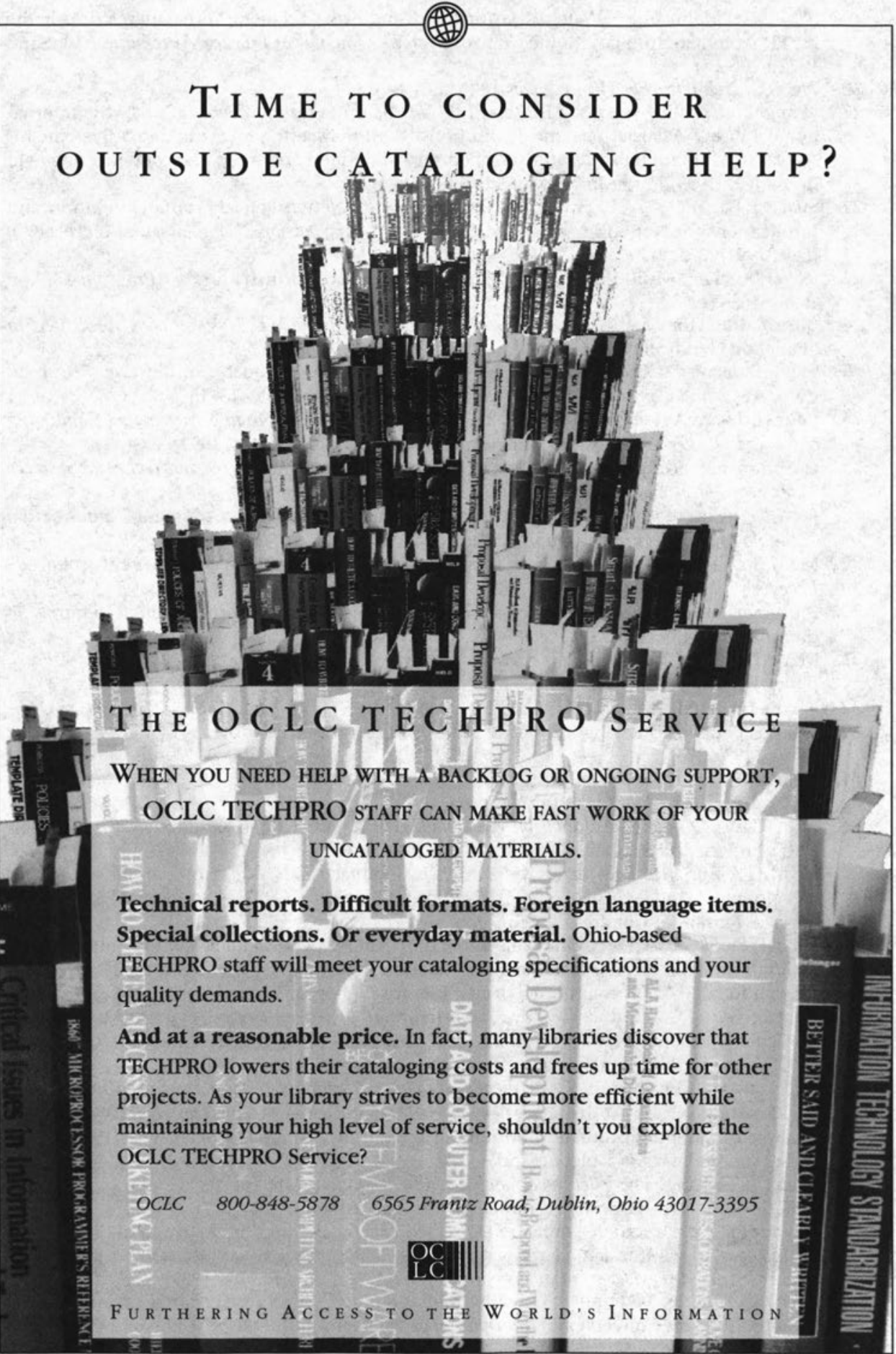

